calculations by Hartree-Fock techniques. Work by Fischer on the AlI isoelectronic sequence is of particular interest; she explained some unexpectedly low oscillator strengths in Sirl. For highly ionized atoms intermediate coupling calculations must be performed, and configuration interaction must often be included as well. Intermediate coupling calculations were reviewed in (3); among more recent papers we mention the work of Mendlowitz on TiII. Examples of configuration interaction calculations include papers by Froese on various stages of ionization of iron and silicon and of Weiss on $\mathrm{Cr}$ and $\mathrm{CI}$ and on AlI. A number of calculations of oscillator strengths including electron correlation effects have been made by Sinanoglu and his students.

Many problems remain to be studied. Perhaps the most important is in the area of the oscillator strengths of high-excitation-potential lines in atoms such as FeI. Independent measurements of oscillator strengths for some such lines by methods which do not involve a knowledge of Boltzmann factors are greatly desired to check on excitation potential effects in the existing measurements, and to place existing measurements on a more reliable absolute scale.

Recent work on forbidden lines was reviewed in (5). Confidence in the reliability of the theoretical results has been increased to some extent by Thackeray's comparisons of [Fem] and [NiII] intensities in $\eta$ Carinae with theoretical intensities. Laboratory experiments by Hults on [PbI] and [PbII] lines in which there is a mixture of magnetic dipole and electric quadrupole radiation tend to confirm the theoretical ratios of these two types of radiation. Measurements of some ratios of lines in [OI] and in [SI] by LeBlanc, Oldenberg and Carleton, and by McConkey, Burns, Moran, Kernahan and Emeleus are in excellent agreement with the theory. Garstang has calculated the transition probabilities for a number of magnetic quadrupole transitions, and showed that one line in each of Ferx, FexvII and Fexxv may be a significant contributor to the de-excitation process in these ions in the solar corona. The $2{ }^{3} S_{1}-1{ }^{1} S_{0}$ line in the helium isoelectronic sequence has been shown by Griem to be due to magnetic dipole radiation made possible in a relativistic approximation.

\title{
REFERENCES
}

1. Wiese, W. L., Smith, M. W., Miles, B. M. 1969, Nat. Stand. Ref. Data System - NBS 22. Atomic transition probabilities, Vol. II.

2. Miles, B. M., Wiese, W. L. 1970 , Nat. Bur. Stand. Special Pub. 320.

3. Layzer, D., Garstang, R. H. 1968, A. Rev. Astr. Astrophys., 6, 449.

4. Bashkin, S. 1968, Beam-foil Spectroscopy, 2 vols., Gordon and Breach, New York.

5. Garstang, R. H. 1969, Mém. Soc. r. Sci. Liège, 17, 35-44.

6. Baschek, B., Garz, T., Holweger, H., Richter, J. $\quad 1969$, Astr. Astrophys. 2, 274-279 and 446-450; 1970, Astr. Astrophys. 4, 229-233.

R. H. GARSTANG

Chairman of the Committee

COMMITTEE 3: COLLISION CROSS SECTIONS AND LINE BROADENING

\section{LINE BROADENING}

Two review articles have been published $(1,2)$.

1.1. Collision broadening by neutral atoms. The continued study of widths and shifts produced by neutral atom impacts at low densities has shown that the Van der Waals interaction $\left(-\mathrm{C}_{6} r^{-6}\right)$ as used, for example, in (3), is an inadequate representation of the interatomic potential. The classical theory for a Leonard-Jones potential $\left(\mathrm{C}_{12} r^{-12}-C_{6} r^{-6}\right)$ has been developed (4) and subjected to experimental test (5). Further improvements result from introducing a term $\mathrm{C}_{8} r^{-8}$ in the potential (6) and from allowance for quasi-static effects (7). Applications to broadening by $\mathrm{H}$-atom impact are discussed in (8).

Progress has been made in the study of resonance broadening (collisions between atoms of the 
same kind). The theory has been subjected to further experimental test (9), and a study has been made of combined resonance interaction and dispersion interaction (10). Calculations (11) and experiment (12) for alkali atoms give information applicable to hydrogen (12).

1.2. Line broadening by charged particles. New and more general theoretical approaches have been developed $(13,14)$. The theory of Stark broadening of hydrogen lines has been improved $(15,21)$ and extended to lower densities and higher quantum numbers (17), and semi-empirical formulae have been given for line wings (18). The Ly $\alpha$ line has been studied, with special emphasis on the contribution from strong impacts $(19,20)$. Further calculations have been made for HeI lines, with forbidden components, using a theory similar to that used for $\mathrm{HI}_{\mathbf{I}}(\mathbf{2 2}, \mathbf{2 3}, \mathbf{2 4})$.

Semi-classical impact theory has been applied to many lines of atoms and ions, and it has been shown that the domain of validity of the theory is greater than has been previously supposed (25). The method has been critically reviewed (26). Refinements in the theory for isolated lines of neutral atoms do not give significant changes in calculated results (27). For positive ions the approximation of rectilinear paths has been abandoned; the use of hyperbolic paths gives substantially greater widths, in better agreement with experiment (25) and with quantum mechanical calculations using reactance matrices obtained from close-coupling calculations for $\mathrm{Mg}$ II (28a) and Ca II (28b). A semiempirical formula may be used for approximate calculations (29).

In turbulent plasmas collective fields can be more important than Holtmark fields (30).

\section{COLLISION CROSS SECTIONS}

2.1. Data services. We again draw attention to the important services provided by two Information Centers; details are given in our last report (31). A new journal is devoted to publication of atomic data (32).

2.2. General reviews and bibliographies. A second edition of a standard work of reference is being published in four volumes (33). Complete abstracts have been published of papers given at two international conferences on atomic collisions (34). Another recent book is concerned with bibliographies on chemical kinetics and collision processes (35); further bibliographies are also available (36).

2.3. Heavy particle collisions at high energies. References are given only to the most recent papers. Impact parameter calculations have been made for excitation of $\mathbf{H ~ b y ~} \mathbf{H}(37,38)$ and by $\mathrm{He}(39)$, and it has been shown that a simple approximation is reliable over an extensive range (39). Born calculations have been made for excitation of $\mathrm{He}$ by $\mathrm{H}(\mathbf{4 0})$, and $\mathrm{H}$ by $\mathrm{H}^{+}(\mathbf{4 1}, \mathbf{4 2})$. Excitation of $\mathrm{H}$ by $\mathrm{H}^{+}$has also been studied using other approximations $(43,44,45)$. Ionization by fast $\mathrm{H}^{+}$has been studied for $\mathrm{H} \mathrm{(46),} \mathrm{He}$ (47a) and heavier atoms (47b). Calculations have been made for electron loss from fast $\mathrm{H}$ and $\mathrm{He}$ in $\mathrm{H}$ or $\mathrm{He}(48)$ and a simple approximate formula has been given (49). Excitation of $\mathrm{He}$ by $\mathrm{H}^{+}$has been studied in the Born approximation (50) and in a more refined treatment (51). Charge transfer has been studied for $\mathrm{H}^{+}$in ground-state $\mathrm{H}(52)$ and $\mathrm{He}(\mathbf{5 3})$, and excited-state $\mathrm{H}$ (54). Various other calculations have been made for fast $\mathrm{H}-\mathrm{H}^{+}$collisions $(55,56)$. Studies of the stopping of fast $\mathbf{H}$ in $\mathbf{H ~ ( 5 7 )}$ are of importance for theories of the solar wind.

We mention an earlier review (58), not cited in our last report, on heavy particle collision processes of importance in astrophysics, at both high energies and low energies.

2.4. Heavy particle collisions at low energies. Excitation of forbidden lines by heavy particle impact has been reviewed (59). Further work has been done on excitation of fine-structure transitions by proton impact (60).

New calculations (61) for radiative attachment of $\mathrm{C}$ and $\mathrm{H}$, and of $\mathrm{C}^{+}$and $\mathrm{H}$, give rate coefficients much larger than earlier estimates. Further rate coefficient calculations have been made for associative detachment of $\mathrm{H}+\mathrm{H}^{-}(62,63)$. A rate coefficient of $2 \times 10^{-5} / T \mathrm{~cm}^{3} \mathrm{sec}^{-1}(T$ in $\mathrm{K})$ has been 
reported for $\mathrm{H}^{+}+\mathrm{H}^{-}$mutual neutralisation (64). Theoretical studies have been made of Penning ionization $(65,66)$. Further work has been done on rotational excitation of $\mathrm{H}_{2}$ by $\mathrm{H}$ impact $(67,68)$ but serious uncertainties remain. Recent work (67; see also 59) suggests that earlier estimates of the cross sections for $\mathrm{O}^{3} P_{J} \rightarrow{ }^{3} P_{J^{\prime}}$ by $\mathrm{H}$ impact, are in error by a factor of about 3 . Improved calculations have been made for transitions between hyperfine structure levels in the $\mathrm{H}$ ground state, by $\mathrm{H}$ impact (69). Calculations based on a shape-resonance model have been made for three-body association, $\mathbf{H}+\mathbf{H}+\mathbf{M} \rightarrow \mathbf{H}+\mathbf{M}$ (70).

A bibliography of work on ion-molecule reaction rate data is available (71).

2.5. Electron collisions with molecules. Review articles have been published on experimental (72) and theoretical $(\mathbf{7 3}, \mathbf{7 4})$ work concerned with excitation of rotation and vibration in simple molecules by slow electrons. In two recent calculations for rotational excitation of $\mathrm{CN}(\mathbf{7 5}, 76)$ different values of the dipole moment have been assumed; an experimental value has now been obtained (77).

A bibliography of work on low energy electron collision cross section data is available (78). There are also bibliographies on electron swarm data (79), and on cross sections for hydrogen and for rare gases $(\mathbf{8 0})$.

2.6. Excitation of atoms and ions by electron impact. A major review article deals with experimental and theoretical aspects of electron impact excitation of atoms (81); further reviews are concerned with electron collisions with atoms (82) and ions (83) and with classical theories (84). Many references in these reviews are not repeated in the present Report. A major advance has been the development of a semi-classical approach, based on the correspondence principle (85), which should give greatly improved cross sections for transitions between highly excited states.

Electron collision processes in gaseous nebulae have been discussed in two review papers $(86,87)$ and work has continued on excitation of forbidden lines in configurations $2 p^{q}(88,89,90,91)$ and $3 p^{q}(92,93,94)$. Further calculations have been made on transitions between levels of $P$ terms in these configurations (95).

The 'close-coupling' approximation has been used to calculate cross sections for excitation of $\mathrm{Mg}^{+}$and $\mathrm{Ca}^{+}(96)$, and cross sections for $2 s^{2} \rightarrow 2 s 2 p^{3} P$ and ${ }^{1} P$ in CII and other ions (97). Some very elaborate calculations for e-H scattering (98) give the best estimates currently available for the near threshold excitation of the $n=2$ levels. Similar calculations have been made for excitation of $\mathrm{He}^{+}(99)$.

Large numbers of cross sections for excitation of positive ions are required for the interpretation of coronal and chromospheric spectra. A detailed study has been made of the semi-empirical $\bar{g}$ formula (100). General computer programs are being developed, for the more accurate calculation of large numbers of cross sections (101).

A general review of excitation and ionization by electron impact, with emphasis on processes of astrophysical importance, is being prepared for publication (102).

2.7. Ionization by electron impact. An earlier review of experimental work has been followed by a companion review of the theory of electron-impact ionization (103). Several other papers have been concerned with reviews of available data and calculation of rate coefficients $(104,105,106)$.

The most important recent advances, so far as astrophysical applications are concerned, have been concerned with work on the ionization of positive ions. References to experimental work are given in (107) and to theoretical work in (108). It has been confirmed that the Coulomb-Born approximation for ionization of ions is more accurate than the Born approximation for ionization of neutrals. Using a general computer program (109), Coulomb-Born calculations can be made for many different ions.

2.8. Recombination. Some further work has been done on the theory of dielectronic recombination at low densities $(110,111,112)$, and a detailed study has been made of the effects of additional collisional processes which become important at higher densities (113). 


\section{REFERENCES}

1. Traving, G. 1968, Plasma Diagnostics, Ed. W. Lochte-Holtgreven. North-Holland Publ. Co., Amsterdam.

2. Ben-Reuven, A. 1969, Adv. at. molec. Phys., 5, 201.

3. Warner, B. 1968, Z. Astrophys., 69, 161.

4. Hindmarsh, W. R., Petford, A. D., Smith, G. $\quad$ 1967, Proc. R. Soc., A297, 296.

5. Vaughan, J. M., Smith, G. 1968, Phys. Rev., 166, 17.

6. Hindmarsh, W. R., du Plessis, A. N., Farr, J. M. to be published.

7. Behmenburg, W. 1968, Z. Astrophys., 69, 368.

8. Roueff, E., van Regemorter, H. 1968, Astr. Astrophys., 1, 69.

9. Kuhn, H. G., Lewis, E. L. $\quad 1967$, Proc. R. Soc., A299, 423.

10. Lewis, E. L. $\quad 1967$, Proc. Phys. Soc., 92, 817.

11. Stacey, D. N., Cooper, J. 1969, Phys. Lett., 30A, 49.

12. Gompertz, G., Hindmarsh, W. R. 1969, Mon. Not. R. astr. Soc., 142, 97.

13. Smith, E. W., Hooper, C. F. $\quad$ 1967, Phys. Rev., 157, 126.

14. Zaidi Haider, R. 1968, Phys. Rev., 173, 132.

15. Kepple, P., Griem, H. R. 1968, Phys. Rev., 173, 317.

16. Smith, E. W., Cooper, J., Vidal, C. R. $\quad 1969$, Phys. Rev., 185, 140; see also D. Voslamber, 1969, Z. Naturf., 24A, 1458.

17. Bengston, R. D., Kepple, P., Tannich, J. D. Phys. Rev. in press.

18. Edmonds, F. N., Schlüter, H., Wells, D. C. $\quad$ 1967, Mem. R. astr. Soc. 71, 271.

19. Shen, K. Y., Cooper, J. 1969, Astrophys. J., 155, 37.

20. Pfenning, $H$. to be published.

21. van Regemorter, H. 1969 , Phys. Lett., 30A, 365.

22. Griem, H. R. 1968, Astrophys. J., 154, 1111.

23. Gieske, H. A., Griem, H. R. 1969, Astrophys. J., 157, 963.

24. Barnard, A. J., Cooper, J., Shamey, L. J. 1969 , Astr. Astrophys., 1, 28.

25. Sahal-Brechot, S. 1969, Astr. Astrophys., 1, 91 and 2, 322.

26. Roberts, D. E. $\quad 1968$, J. quantit. Spectrosc. radiat. Transfer, 8, 1241.

27. Cooper, J., Oertel, G. K. $\quad$ 1969, Phys. Rev., 180, 286.

28. (a) Bely, O., Griem, H. R. $\quad$ 1970, Phys. Rev., in press; (b) Barnes, K. S., Peach, G. 1970, Nature, 225 , 374.

29. Griem, H. R., 1968, Phys. Rev., 165, 258.

30. Kunze, H.-J., Griem, H. R. 1968, Phys. Rev. Lett., 21, 1048; and 1969, ibid., 23, 1279.

31. Trans. IAU, 13A, 1967, 239.

32. Atomic Data: A Journal Devoted to Compilations of Experimental and Theoretical Results in Atomic Physics, Academic Press, New York and London.

33. Electronic and Ionic Impact Phenomena, Oxford Univ. Press: Vol. I: H. S. W. Massey, E. H. S. Burhop, Electron Collisions with Atoms, 1969; Vol. II: H. S. W. Massey, Electron Collisions with Molecules Photo-Ionization, 1969; Vol. III: H.S. W. Massey, Slow Collisions of Heavy Particles, in press; Vol. IV: H. S. W. Massey, E. H. S. Burhop, H. B. Gilbody, Fast Collisions of Heavy Particles Recombination - Slow Collisions with Positrons and Muons, in preparation.

34. (a) Abstracts of Papers, 5th Int. Conf. Phys. Electr. and Atomic Coll., Nauka Publ. House, Leningrad, 1967; - (b) 6th Int. Conf., M.I.T. Press, Cambridge, Mass., 1969.

35. Bibliography of Chemical Kinetics and Collisions Processes. Ed. A. R. Hockstim, Plenum Press, New York, 1969.

36. The following bibliographies on Atomic Collisions are available from Dr. K. Takayanagi, Institute of Space and Aeronautical Studies, University of Tokyo: No. 5 and No. 6., Ionic Impact (experimental); No. 7, Heavy Particle Collisions with Electronic Transitions (theoretical); No. 8, Electron Collisions with Atoms and Molecules (experimental).

37. Levy, H. 1969, Phys. Rev., 184, 97.

38. Flannery, M. R. 1969, J. Phys. B: At. Molec. Phys. 2, 909; and Phys. Rev., 183, 231 and 241.

39. Flannery, M. R. 1969, J. Phys. B: At. Molec. Phys., 2, 913.

40. Levy, H. 1969, Phys. Rev., 185, 7.

41. Khandelwal, G. S., Choi, B.-H. 1968, J. Phys. B: At.Molec.Phys.,1,1218 and 1220; 1969, ibid., 2, 308.

42. Khandelwal, G. S. 1969, J. Phys. B: At. Molec. Phys., 2, 151.

43. Coleman, J. P. $\quad$ 1968, J. Phys. B: At. Molec. Phys., 1, 567. 
44. Holt, A. R., Moiseiwitsch, B. L. 1968, J. Phys. B: At. Molec. Phys., 1, 36.

45. Flannery, M. R. $\quad$ 1969, J. Phys. B: At. Molec. Phys., $2,1044$.

46. Salin, A. 1969, J. Phys. B: At. Molec. Phys., 2, 631.

47. (a) Bell, K. I., Kingston, A. E. 1969 , J. Phys. B: At. Molec. Phys., 2, 653; (b) Peach, G., 1968, J. Phys. B: At. Molec. Phys., 1, 1088.

48. Bell, K. L., Dose, V., Kingston, A. E. 1969, J. Phys. B: At. Molec. Phys., $2,831$.

49. Victor, G. A. 1969, Phys. Rev., 184, 43.

50. Bell, K. L., Kennedy, D. J., Kingston, A. E. 1968, J. Phys. B: At. Molec. Phys., 1, 218, 1028 and 1037.

51. Van den Bos, J. 1969, Phys. Rev., 181, 191.

52. Mapleton, R. A. $\quad 1968$, J. Phys. B: At. Molec. Phys., 1, 529.

53. Colegrave, R. K., Stephens, D. B. L. $\quad 1968$, J. Phys. B: At. Molec. Phys., 1, 856.

54. Bates, D. R., Reid, R. H. G. $\quad$ 1969, J. Phys. B: At. Molec. Phys., 2,851 and 857.

55. Gallaher, D. F., Willets, L. $\quad$ 1968, Phys. Rev., 169, 139; see also I. M. Cheshire, D. R. Gallaher, A. J. Taylor in (34b).

56. Coleman, J. P., Trelease, S. $\quad$ 1968, J. Phys. B: At. Molec. Phys., 1, 172.

57. Schafer, J., Trefftz, E. to be published.

58. Dalgarno, A. 1967, Rev. Mod. Phys., 39, 850.

59. Dalgarno, A., Reid, R. H. G. 1969, Mém Soc. r. Sci. Liege, 17, 57.

60. Reid, R. H. G., Schwartz, J. in (34b).

61. Klemperer, $W$. to be published.

62. Chen, J. C. Y., Peacher, J. L. 1968, Phys. Rev., 167, 30.

63. Browne, J. C., Dalgarno, A. 1969, J. Phys. B: At. Molec. Phys. 2, 885.

64. Victor, G. A. to be published.

65. Nakamura, H. 1969, J. phys. Soc. Japan, 26, 1473.

66. Mori, M. 1969, J. phys. Soc. Japan, 26, 773.

67. Nishimura, S. 1968, Ann. Tokyo astr. Obs., 11, 33.

68. Tang, K. J. Chem. Phys., in press.

69. Allison, A. C., Dalgarno, A. 1969, Astrophys. J., 158, 523.

70. Roberts, R. E., Bernstein, R. B., Curtis, C. F. 1969, J. Chem. Phys. 50, 5163.

71. Sinnott, G. A. 1969, Bibliography of Ion-Molecule Reaction Rate Data, JILA Information Center Report No. 9 (Joint Inst. Lab. Astrophys., Boulder, Colo.).

72. Phelps, A. V. 1968, Rev. Mod. Phys., 40, 399.

73. Takayanagi, K. 1967, Progress theor. Phys. (Kyoto), Suppl. No. 40, 216.

74. Takayanagi, K., Itikawa, Y. 1970, Adv. At. Molec. Phys., 6.

75. Takayanagi, K., Itikawa, Y. 1968, Publ. astr. Soc. Japan, $20,376$.

76. Allison, A. C., Crawford, O. H., Dalgarno, A., 1969, Astr. Astrophys., 2, 451.

77. Thomson, R., Dalby, F. W. 1968, Can. J. Phys., 46, 2815.

78. Kieffer, L. J. 1969 , Atomic Data, 1, 19 and 122.

79. Dutton, J. 1967, Bibliography of Electron Swarm Data, JILA Information Center Report, No. 4 (Joint Inst. Lab. Astrophys., Boulder, Colo.).

80. Laborie, P., Rocard, J.-M., Rees, J. A. 1968, Tables des Sections Efficaces Electroniques et Coefficients Macroscopiques: I: Hydrogéne et gaz rares. McGraw Hill, New York.

81. Moiseiwitsch, B. L., Smith, S. J. 1968, Rev. Mod. Phys., 40, 238.

82. Burke, P. G. 1969, Atomic Physics, Ed B. Bedersen, V. W. Cohen and F. M. J. Pichanick. Plenum Press, New York, p. 265.

83. Seaton, M. J. 1969, Atomic Physics, Ed. B. Bedersen, V. W. Cohen and F. M. J. Pichanick. Plenum Press, New York, p. 295.

84. Burgess, A., Percival, 1. C. $\quad$ 1968, Adv. At. Molec. Phys., 4, 109.

85. Percival, I. C., Richards, D. 1969, Astrophys. Lett., 4, 235.

86. Seaton, M. J. 1968, Adv. At. Molec. Phys., 4, 331.

87. Seaton, M. J. 1969, Mém. Soc. r. Sci. Liege, 17, 45.

88. Saraph, H. E., Seaton, M. J., Shemming, J. 1969, Phil. Trans. R. Soc., A264, 77.

89. Smith, K., Conneely, M. J., Morgan, L. A. 1969 , Phys. Rev., 177, 196.

90. Henry, R. J. W., Burke, P. G., Sinfailam, A.-L. 1969, Phys. Rev., 178, 218.

91. Eissner, W., Martins, P. de A. P., Nussbaumer, H., Saraph, H. E., Seaton, M. J. $\quad$ 1969, Mon. Not. R. astr. Soc. 146, 63.

92. Czyzak, S. J., Krueger, T. K. 1967, Proc. Phys. Soc., 90, 623. 
93. Conneely, M. J., Smith, K., Lipsky, L. submitted to J. Phys. B: At. Molec. Phys.

94. Czyzak, S. J., Krueger, T. K., Martins, P. de A. P., Saraph, H. E., Seaton, M. J. Mon. Not. R. astr. Soc., in press.

95. Blaha, M. 1968, Ann. Astrophys., 31, 311; 1969, Astr. Astrophys., 1, 42.

96. Burke, P. G., Moores, D. L. 1968, J. Phys. B: At. Molec. Phys., 1, 575.

97. Osterbrock, D. E. Astrophys. J., in press; and J. Phys. B: At. Molec. Phys., in press.

98. Burke, P. G., Ormonde, S., Whitaker, W. 1967, Proc. Phys. Soc., 92, 319; A. J. Taylor and P. G. Burke, ibid., 336; P. G. Burke, A. J. Taylor, S. Ormonde, ibid., 345; J. Macek and P. G. Burke, ibid., 351 ; J. Macek, ibid., 365.

99. Burke, P. G., Taylor, A. J. 1969, J. Phys. B: At. Molec. Phys., $2,44$.

100. Blaha, M. 1969, Astrophys. J., 157, 473.

101. Eissner, W., Seaton, M. J. see (34b).

102. Bely, O., Van Regemorter, H. 1970 , to appear in A. Rev. Astr. Astrophys., 8.

103. Rudge, M. R. H. 1968, Rev. Mod. Phys., 40, 564.

104. Gulyaev, R. A. 1967, Sov. Astr. - AJ., 10, 761.

105. Lin, Sin-Shong, Stafford, F. E. 1968, J. Chem. Phys., 48, 3885.

106. Lotz, W. 1968, Z. Phys., 216, 241.

107. Peart, B., Dolder, K. T. 1969, J. Phys. B: At. Molec. Phys., 2, 1169; Peart, B., Martin, S. O., Dolder, K. T. ibid., 1176.

108. Bely, O. and Schwartz, S. B. 1969 , Astr. Astrophys., 1, 281 ; Sato, S., Takahashi, K., and Takebe, H., 1968, Publ. astr. Soc. Jap., 20, 149.

109. Eissner, W., Moores, D. L. $\quad$ see (34b).

110. Trefftz, E. 1969, Proc. Sommerfeld Memorial Meeting, Munich, North-Holland Publ. Co., Amsterdam.

111. Davies, P. C. W., Seaton, M. J. 1969, J. Phys. B: At. Molec. Phys., 2, 757.

112. Trefftz, E. J. Phys. B: At. Molec. Phys., in press.

113. Burgess, A., Summers, H. P. $\quad$ 1969, Astrophys. J., 157, 1007.

M. J.SEATON

Chairman of the Committee

\section{COMMITTEE 4: STRUCTURE OF ATOMIC SPECTRA}

\section{General work on Atomic Spectra}

A current Bibliography on The Analyses of Optical Atomic Spectra is in print (43). It appears in four sections, three of which cover the same elements as the respective volumes on Atomic Energy Levels. Relevant literature references from the dates of publication of these Volumes are continued for each spectrum to the present, as follows:

$$
\begin{array}{lll}
\text { Section } 1 & { }^{1} \mathrm{H}-{ }^{23} \mathrm{~V} & \text { issued September } 1968 . \\
\text { Section } 2 & { }^{24} \mathrm{Cr}-{ }^{41} \mathrm{Nb} & \text { issued February } 1969 . \\
\text { Section } 3\left\{\begin{array}{l}
{ }^{42} \mathrm{Mo}-{ }^{57} \mathrm{La} \\
{ }^{72} \mathrm{Hf}-{ }^{89} \mathrm{Ac}
\end{array}\right\} & \text { issued May } 1969 .
\end{array}
$$

The last Section contains references to rare-earth spectra:

$$
\text { Section } 4\left\{\begin{array}{l}
{ }^{57} \mathrm{La}-{ }^{71} \mathrm{Lu} \\
{ }^{89} \mathrm{Ac}-{ }^{99} \mathrm{Es}
\end{array}\right\} \text { issued September } 1969 .
$$

The present report will be limited to later work.

Monographs, extended analyses, work in progress

The active programs in Lund are providing data on atomic spectra that are urgently needed. In the Physics Department of the University, Edlén and his colleagues have published or submitted 